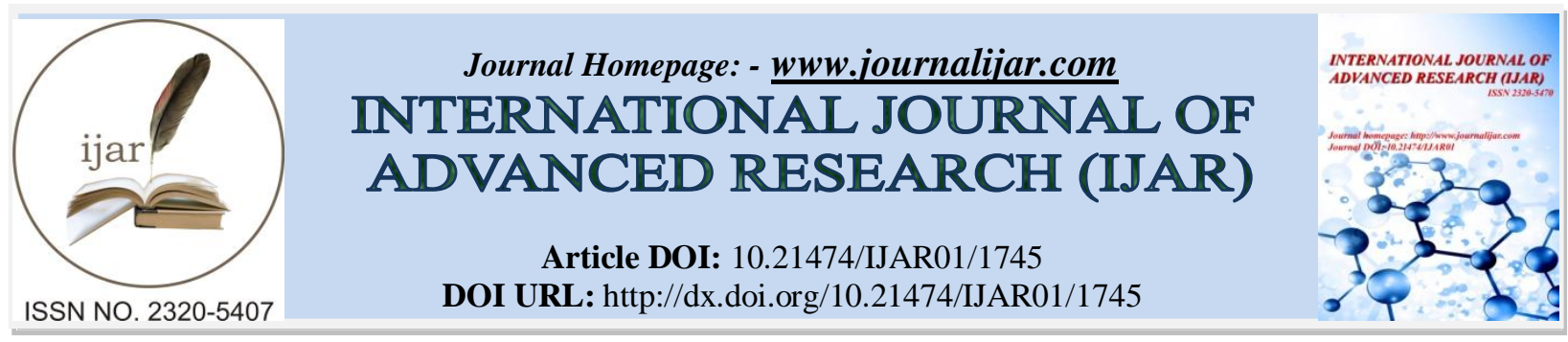

RESEARCH ARTICLE

\title{
STRESS AMONG FEMALE UNDERGRADUATE STUDENTS AT UNIVERSITY OF DAMMAM, SAUDI ARABIA (2012).
}

\section{Bayan A. Alnassir, Fatima A. AlRadhi, Hajar Y. AlYagout, Hanan A. Alhawaj, Reema H. Bukhamseen, Sara A. Altarouti and Zahra A. Al-Ibrahim. \\ Department of Family and Community Medicine, College of medicine and medical sciences, Arabian Gulf University, Bahrain.}

\section{Manuscript Info}

Manuscript History

Received: 12 July 2016

Final Accepted: 22 August 2016

Published: September 2016

Key words:-

Stress, Undergraduate Students, Saudi Arabia.

\begin{abstract}
Researchers have studied Stress among university students over the years. Because of the effects it has on health and academic performance. The aim of this study was to study stress by measuring its level, identifying its sources and how to cope with it among female students in the University of Dammam in Saudi Arabia in the year of 2012.A cross-sectional study design was used. The data was collected by administering questionnaires to the students. The results indicated that students experienced moderate levels of stress and faced stressors from three sources: academic, social and financial, but mainly from the academic source. The levels of stress differed between different specialties with medical students scoring higher levels of stress than non-medical students. Coping with stress responses showed that sleeping was the preferred method for coping followed by surfing the Internet and watching TV. The stress level in University of Dammam needs attention and intervention. Offering students counseling programs for social, academic and psychological stressors will help reduce the stress level and leave them in a healthy mental state.
\end{abstract}

Copy Right, IJAR, 2016,. All rights reserved.

\section{Introduction:-}

Stress among university students has been the subject of interest of researchers for many years. It is generally believed that stress is one of the most important issues that affect university students' lives because they have to adapt socially and academically to a new environment (1).Its effects could be reflected in the students' behavior, social life, academic performance, and mental health (2-3).

Stress among university students has been well documented, there have been much research in this field and it all indicated that this area needed more attention because of the high prevalence of stress in university students' especially female students (3-10).

\section{Literature Review:-}

A number of researches shown gender differences in the prevalence and level of stress among national university students and found that Female students had higher prevalence and higher levels of stress than their male counterparts (5).

Corresponding Author:- Bayan A. Alnassir.

Address:- Department of Family and Community Medicine, College of medicine and medical sciences, 1444 
Also in the USA, a study was conducted on international students attending universities in USA concluded that female students had higher reactions to stressors such as life and academic stressors than male students (6).

In USA, a study was done to determine the stress level in nursing students found a significant difference when gender was used as a variable. Females reported higher levels of stress (7).

Another study was done about stress in medical students in different parts of Canada discovered that in these areas female students reported higher levels of stress (8).

In Turkey a study was done in university students used Depression Anxiety Stress Scale (DASS-42) found that female student's scores were higher than male students in which a low score indicate low level of stress and a higher score indicate higher level of stress (9).

In Ghana, a research was done on first year university students. They used Perceived Stress Scale (PSS). Results indicated that $1^{\text {st }}$ year female students had significantly higher levels of stress compared to $1^{\text {st }}$ year male students (10).

In Saudi Arabia, Eastern province, in Dammam university research was done on the subject of: A Comparative Study of Perceived Stress among Female Medical and Non-Medical University Students. The authors concluded that medical students were at a higher risk of physical and mental problems than non-medical students because of academic stress (3).

\section{Significance of the Study:-}

Many undergraduate female students experience stress, that is why many researches is conducted in this field. In Saudi Arabia there isn't enough research covering this subject to identify the magnitude and the extent of this problem. Our purpose was to study stress in female undergraduate students in the University of Dammam in Saudi Arabia to gain enough depth about this hidden problem.

\section{Aim:-}

To study stress among female undergraduate students in the University of Dammam, Eastern province, Saudi Arabia.

\section{Objectives:-}

1. To measure the level of stress among female undergraduate students of different specialties.

2. To identify the sources of stress among female undergraduate students.

3. To find out the mechanisms used by female undergraduate students to deal with stress.

\section{Material And Methods:-}

Study Design:-

A cross sectional study was chosen, because of times constrains and low cost.

\section{Study Population:-}

The target population of our research was the Female undergraduate students of university of Dammam.

\begin{tabular}{|l|l|}
\hline College & No. Of female students \\
\hline College of Medicine & 488 \\
\hline College of Nursing & 368 \\
\hline College of Applied Medical Sciences & 354 \\
\hline College of Applied Studies and Community Service Branch & 1454 \\
\hline College of Business Administration Branch & 795 \\
\hline Department of Interior Design & 169 \\
\hline Medicine Parallel Program & 244 \\
\hline Total & 3872 \\
\hline
\end{tabular}

\section{Sample Size:-}

The sample size was determined using the following equation: 
First calculating it for infinite population using this formula:

$\mathrm{SS}=\underline{\mathrm{Z}^{*}(p) *(1-p)}=384$

$\mathrm{c}^{2}$

Where:-

$\mathrm{SS}=$ sample size

$\mathrm{Z}=\mathrm{Z}$ value $=1.96$ for $95 \%$ confidence level $)$

$\mathrm{p}=$ percentage picking a choice $=.5$

$\mathrm{c}=$ confidence interval $=.05$

Pop $=$ the target population $=3872$

Second correcting it for finite population using this formula:

New SS $=\frac{\text { SS }}{\frac{\left[1+\frac{(\text { SS }-1)]}{\text { Pop }}\right.}{2}}=350$

\section{Sampling Technique \& Procedure:-}

Stratified random sampling technique was used. The population was divided into 6 strata based on the specialty. By proportionate stratificationthe sample size of each stratum is proportionate to the population size of the stratum. Strata sample sizes were determined by the following equation:

$\mathrm{n}_{\mathrm{h}}=\left(\mathrm{N}_{\mathrm{h}} / \mathrm{N}\right) * \mathrm{n}$

Where $\mathbf{n}_{\mathbf{h}}$ is the sample size for stratum $\mathrm{h}, \mathbf{N}_{\mathbf{h}}$ is the population size for stratum $\mathrm{h}, \mathrm{N}$ is total population size, and $\mathrm{n}$ is total sample size.

The questionnaire was administered through "Google Survey "TM . This method of data collection is more efficient these days and it allows reaching as many students as possible. Because of this, the responses were collected from social networking sites such as Facebook and Twitter. Also, from e-mails such as Hotmail, Gmail and from Blackberry Messenger.

Case Definition:-

- Inclusion criteria:any Saudi Female undergraduate student attending the university of Dammam in 2012.

- Exclusion criteria: female students from a different nationality.

\section{Study Instrument:-}

A 50-item questionnaire divided into 3 sections:

The first section was taken from Depression Anxiety Stress Scale (DASS-42) by using only the stress scale, which consisted of 14 items; the company who developed the DASS allows everyone to use it with no need of asking for permission. The second section was 25 items identifying the sources of stress whether academic, social/family or financial and the third section was 10 items aimed to find out what were the activities done by students to relieve stress.

\section{Study variables:-}

The questioner was divided into 3 main sections, which include:

Demography: age, BMI, marital status, academic year and specialty

* Accommodation

- Source of stress: academic, social/family and financial.

\section{Pilot Study:-}

A pilot study was done on 25 students from the relative population. It showed that certain items in the questionnaire had to be written in a simpler language, other items needed more definition to be more specific so that it can achieve the aim and the objectives.

\section{Data Entry:-}

The data was automatically compiled into Google Doc. Then Exported to SPSS v20 where the analysis of the data took place. 


\section{Data Analysis:-}

The data was analyzed using a specialized statistical program, which is SPSS v20. Descriptive statistics was used to describe the outcome such as the mean and standard deviation. The statistical tests, which were used, were; ANOVA, Post-Hoc and the paired sample t-test.

\section{Verification of Data:-}

After entry of data it was be inspected by all of the group members looking for any mistakes. If mistakes were found they were immediately fixed to insure full accuracy of the data.

Table.1:- Stress Score in relation to marital status.

\begin{tabular}{|l|l|l|l|}
\hline & N & Mean & Std. Deviation \\
\hline Single & 256 & 22.84 & 9.6 \\
\hline Married & 84 & 22.82 & 8.8 \\
\hline Divorced & 10 & 31.8 & 7.3 \\
\hline Total & 350 & 23.1 & 9.5 \\
\hline
\end{tabular}

\section{Results:-}

In this study, there had been 498 responses. 350 were used to perform statistical analysis. The age of the participants ranged between 18 and 25 years.

The results regarding the stress level in University of Dammam, which were measured by using ANOVA, were as it shows in (Figure.1) with a total mean stress score of 23, which means moderate according to the DASS stress scale. There were difference in mean stress score of different specialties and it was significant because $(\mathrm{p}=.003)$ which is (<.05). By performing the Post-Hoc test the difference was in favor of the medical parallel program, which scored the highest of 28.5 meaning severe stress.

Figure.1:- Stress score in relation to specialties

The results also showed using ANOVA and measuring stress score depending on marital status as seen in Table.1 that divorced students scored the highest of a mean of 31.8 meaning suffering severe stress levels. Single students than married students followed them. The Difference was Significant because $(\mathrm{p}=.013)$ which is below .05

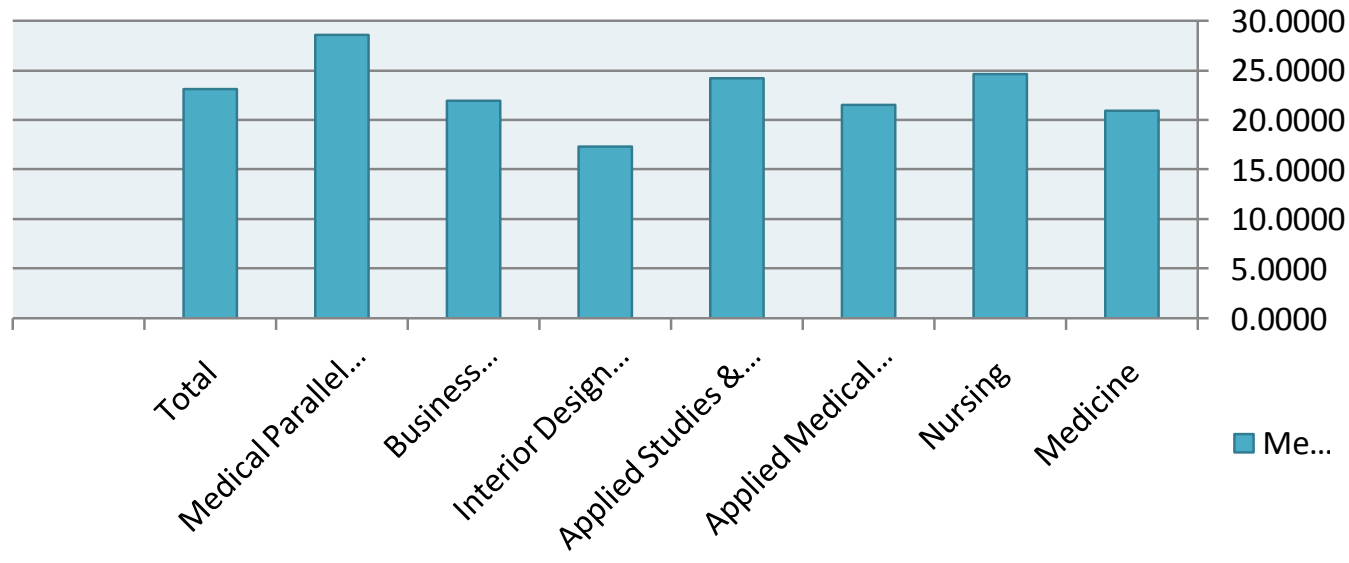

The mean scores of Body mass index (BMI) before and after entering the university were 23.25 and 23.76, respectively. In both cases the result is normal because it lies in the range of (20-25).

The use of paired sample t-test was needed to compare between BMI before and after entering the university. The $p$ value $=.000$ which is below $<.05$, meaning that there is significant difference.

Correlation between BMI and mean stress score revealed that both are highly correlated with a value approaching 1 of $=.845$ 
In identifying the sources of stress, responses regarding the academic section showed in Table. 2 that taking exams scored the highest with $84.9 \%$ followed by studying the material and getting good grades with $77.7 \%$.

In the Social section responses revealed as in Table.3 that maintenance of friendships was the highest with $63.4 \%$ followed by fear of disappointing the family with $59.1 \%$ followed by dealing with family conflict with $55.1 \%$

Table.2:- Academic source of stress

\begin{tabular}{|c|c|c|c|c|c|c|c|c|c|c|c|c|}
\hline & & & & & & & & & & & \\
\hline & & 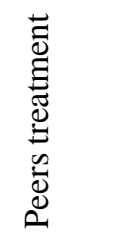 & 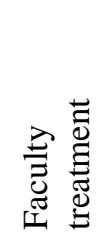 & 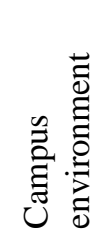 & 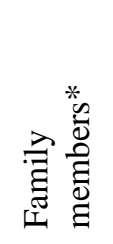 & 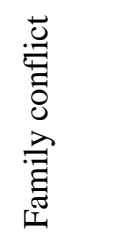 & 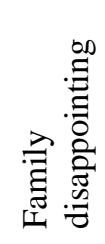 & 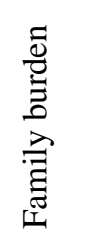 & 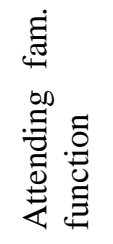 & 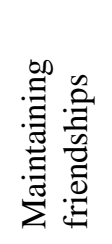 & 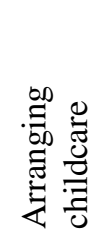 & 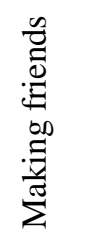 \\
\hline Applicable & $\begin{array}{l}\mathrm{N} \\
(\%)\end{array}$ & $\begin{array}{l}130 \\
(37)\end{array}$ & $\begin{array}{l}149 \\
(42.6)\end{array}$ & $\begin{array}{l}184 \\
(52.6)\end{array}$ & $\begin{array}{l}192 \\
(54.9)\end{array}$ & $\begin{array}{l}193 \\
(55.1)\end{array}$ & $\begin{array}{l}207 \\
(59.1)\end{array}$ & $\begin{array}{l}152 \\
(43.4)\end{array}$ & $\begin{array}{l}145 \\
(41.4)\end{array}$ & $\begin{array}{l}222 \\
(63.4)\end{array}$ & $\begin{array}{l}102 \\
(29.1)\end{array}$ & $\begin{array}{l}179 \\
(51.1)\end{array}$ \\
\hline $\begin{array}{l}\text { Not } \\
\text { Applicable }\end{array}$ & $\begin{array}{l}\mathrm{N} \\
(\%)\end{array}$ & $\begin{array}{l}220 \\
(62.9)\end{array}$ & $\begin{array}{l}201 \\
(57.4)\end{array}$ & $\begin{array}{l}166 \\
(47.4)\end{array}$ & $\begin{array}{l}158 \\
(45.1)\end{array}$ & $\begin{array}{l}157 \\
(44.9)\end{array}$ & $\begin{array}{l}143 \\
(40.9)\end{array}$ & $\begin{array}{l}108 \\
(56.6)\end{array}$ & $\begin{array}{l}205 \\
(58.6)\end{array}$ & $\begin{array}{l}128 \\
(36.6)\end{array}$ & $\begin{array}{l}248 \\
(70.9)\end{array}$ & $\begin{array}{l}171 \\
(48.9) \\
\end{array}$ \\
\hline
\end{tabular}

The results in the financial section as seen in Table.4 showed: management of the weekly budget scored 51.7\% followed by supporting themselves with $48 \%$ followed by paying the university fees with $36.3 \%$.

Table.3:- Social Source of stress

\begin{tabular}{|c|c|c|c|c|c|}
\hline & & 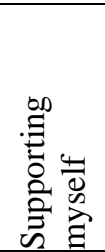 & 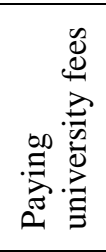 & 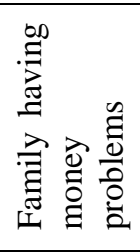 & 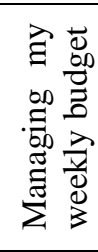 \\
\hline Applicable & $\mathrm{N}(\%)$ & $\begin{array}{l}168 \\
48)(\end{array}$ & $\begin{array}{l}127 \\
(36.3)\end{array}$ & $\begin{array}{l}126 \\
36)(\end{array}$ & $\begin{array}{l}181 \\
51.7)(\end{array}$ \\
\hline Not Applicable & $\mathrm{N}(\%)$ & $\begin{array}{l}182 \\
(52)\end{array}$ & $\begin{array}{l}223 \\
63.7)(\end{array}$ & $\begin{array}{l}224 \\
64)(\end{array}$ & $\begin{array}{l}169 \\
(48.3)\end{array}$ \\
\hline
\end{tabular}

Table.4:- Financial Source of stress

\begin{tabular}{|c|c|c|c|c|c|c|c|c|c|c|c|}
\hline & & 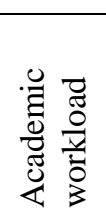 & 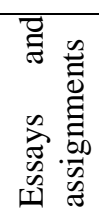 & م0 & 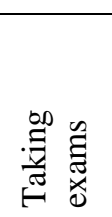 & 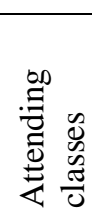 & 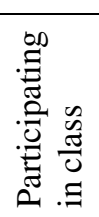 & 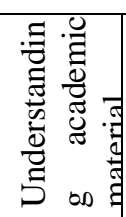 & 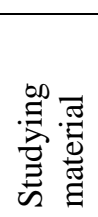 & $\begin{array}{l}\frac{y}{0} \\
\vdots \\
\vdots \\
\vdots \\
0 \\
\dot{0}\end{array}$ & 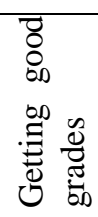 \\
\hline Applicable & $\begin{array}{l}\mathrm{N} \\
(\%)\end{array}$ & $\begin{array}{l}269 \\
(76.9)\end{array}$ & $\begin{array}{l}256 \\
(73.1)\end{array}$ & $\begin{array}{l}270 \\
(77.1)\end{array}$ & $\begin{array}{l}297 \\
(84.9)\end{array}$ & $\begin{array}{l}224 \\
(64)\end{array}$ & $\begin{array}{l}179 \\
(51.1)\end{array}$ & $\begin{array}{l}245 \\
(70)\end{array}$ & $\begin{array}{l}272 \\
(77.7)\end{array}$ & $\begin{array}{l}208 \\
(59.4)\end{array}$ & $\begin{array}{l}272 \\
(77.7)\end{array}$ \\
\hline $\begin{array}{l}\text { Not } \\
\text { Applicable }\end{array}$ & $\begin{array}{l}\mathrm{N} \\
(\%)\end{array}$ & $\begin{array}{l}81 \\
(23.1)\end{array}$ & $\begin{array}{l}94 \\
(26.9)\end{array}$ & $\begin{array}{l}80 \\
(22.9)\end{array}$ & $\begin{array}{l}53 \\
(15.1)\end{array}$ & $\begin{array}{l}126 \\
(36)\end{array}$ & $\begin{array}{l}171 \\
(48.9)\end{array}$ & $\begin{array}{l}105 \\
(30)\end{array}$ & $\begin{array}{l}78 \\
(22.3)\end{array}$ & $\begin{array}{l}142 \\
(40.6)\end{array}$ & $\begin{array}{l}78 \\
(22.3)\end{array}$ \\
\hline
\end{tabular}

Results regarding coping with stress as seen in Figure.2: sleeping scored the highest respond with $67.7 \%$ followed by $54.6 \%$ in surfing the net while smoking scored the lowest with $9.7 \%$. 
Figure.2:- Coping with stress

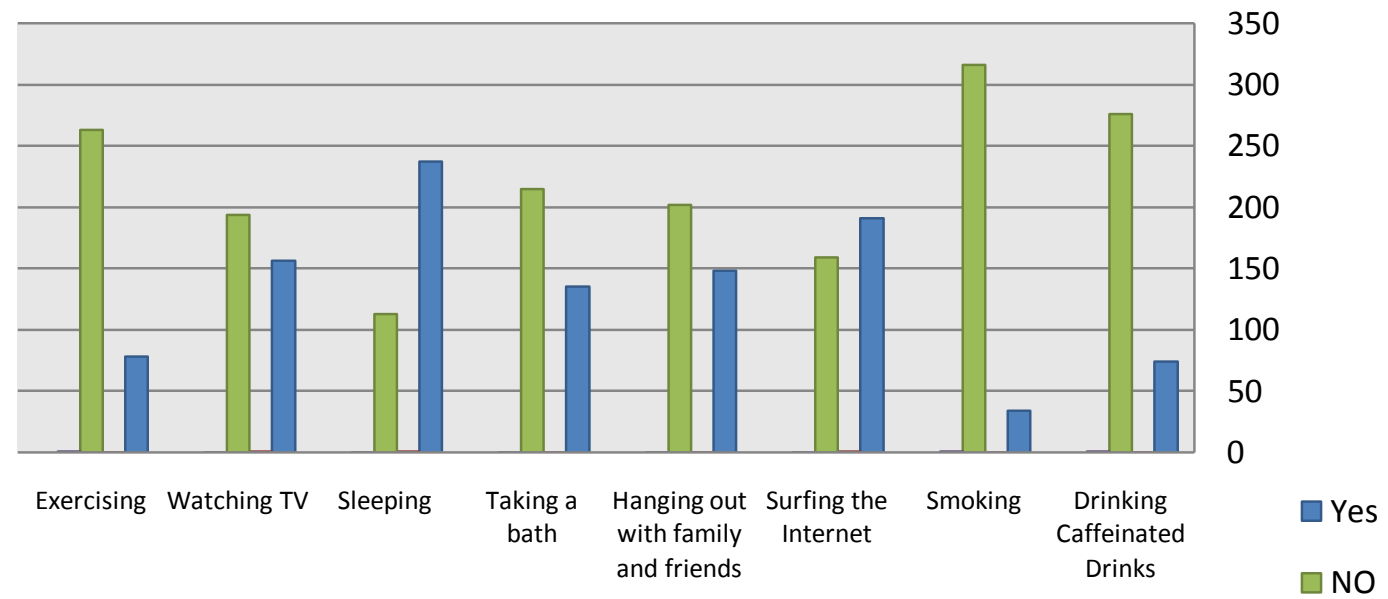

\section{Discussion:-}

The results of this study indicate that female students in University of Dammam experience moderate levels of stress among specialties. The highest score was in the medical parallel program and the least score was in the interior design department. This could be explained by the fact that medicine consumes the time of the students because they have to study a huge number of things in a short period of time. Also, the medical parallel program uses Problem based learning (PBL) as a method of teaching making the students depend on themselves to understand and comprehend the material which puts them in a lot of pressure and increase their level of stress. Comparing the results of this study with previous results on the same topic $(3,8)$ the previous research support the findings of this study that medical students experience a great amount of stress in comparison with other specialties.

The mean stress score was the highest among divorced students followed by single students and the married students scored the lowest. In justifying these findings, divorced female students are more subjected to community pressure and this may lead to the development of many emotional, social and psychological problems that will result in them suffering more stress than the others. Single students came in $2^{\text {nd }}$ place; it may be due to that they are under a lot pressure from the community to get married, since they come from a culture that encourages females to get married in young age. The lowest score was among the married students. This could be explained by that they are more mature since they have their own families and are much better in handling pressure and taking care of themselves and others.

The BMI score had increased after students had entered the university, because may be many students are emotional eaters which mean that they cope with stress by eating more than what they need. Also, students who don't live with their parents depend on fast food and unhealthy drinks to supply their food needs because they don't know how to take care of themselves and eat a healthy diet.

The results show that students experience stress from 3 sources. In the academic section there were three statements, which scored higher, they were fear of taking exams, getting good grades and studying the material. These statements are all related, these are the highest because students have to finish a lot of material in a short period of time and they worry that they won't have enough time to finish the entire exam. Also, students may suffer from sleeping and eating disturbances and even loss of self-confident during this period of time that lead to increased stress. They fear too, if they don't get good grades they won't graduate with high marks and this could affect their job opportunities. The academic section had higher percentages more than the other sections. In comparing this result with other studies (1,3, and 5) all the findings support that students experience academic stress more than any other source.

In the social section, students chose the statement maintaining friendships as a source of stress, May be due to the fact that friendships with friends who are not from the same university makes it harder for them to communicate and meet. Disappointing their families, since they want to make their families proud of them and their achievements followed it. 
Responses of the financial section showed managing the weekly budget had the highest score. It might be due to low monthly income and the constant rise in prices. Supporting themselves financially since they are unemployed and only receive the student salary followed it. The lowest score was for paying the university fees because the universities in Saudi Arabia are mostly governmental and not private.

Coping with stress section revealed that students cope by different manners. They chose sleeping first because they depend on it to clear their minds and get refreshed and recharged. Followed by surfing the Internet because they can go on social networking sites and connect with their friends and also they can search in the Internet for their interests. Watching T.V was the $3^{\text {rd }}$ highest choice because they can watch their favorite movies and shows and be connected to the outside world and the lowest score was for smoking since this is an unhealthy habit and has many consequences on a person's health.

\section{Conclusion And Recommendation:-}

In this study, the findings revealed that students experienced moderate levels of stress. The stress level in University of Dammam deserves attention and requires intervention. The researchers recommend and suggest on the authority in University of Dammam to provide students with a psychological, academic and social counseling in order to decrease the students' stress level. Counseling will help students achieve better in academic performance and have a healthy mental state. University of Dammam also should offer financial support to students who face financial difficulties. Also, they ought to provide students with a suitable and appropriate teaching and learning methods that will help decrease their academic stress.

\section{Acknowledgemen:-}

All our thanks to the participants in this study who responded to our questionnaire during the data collection period and afforded us with their support. We hold special thanks and appreciation to our supervisor Dr. Ahmed Jaradat who provided us with continuous support and feedback during all stages of this research. His effort are highly appreciated and his guidance was crucial in molding and creating this study

\section{Refereces:-}

1. Thawabieh, A. Qaisy, L. (2012). Assessing stress among university students. American International Journal of Contemporary Research. 2(2). Pp 110-116

2. Hamaideh, S. (2011). Stressors and Reaction to Stressors among University Students. International Journal of Social Psychiatry. 57(1). pp. 69-80.

3. Ching, C. (2009). Academic stress and health outcomes among college students.department of applied social studies.city university of hongkong. Pp 73.

4. Al-Dabal, B. Koura, M. Rasheed, P. Al-Sowielem, L. Makki, S. (2010). A Comparative Study of Perceived Stress among Female Medical and Non-Medical University Students in Dammam, Saudi Arabia. Sultan Qaboos University Medical Journal. 10(2). Pp. 231-240.

5. Agolla, J. Ongori, H. (2009). An assessment of academic stress among undergraduate students: The case of University of Botswana. Educational Research and Review. 4(2). Pp. 63-70.

6. Brougham, R. Zail, C. Mendoza, C. Miller, J.Stress, Sex Differences, and Coping Strategies Among College Students. Current Psychology. 28(2). Pp. 85-97.

7. Misra, R. Crist, M. Burant, C. (2003). Relationships Among Life Stress, Social Support, Academic Stressors, and Reactions to Stressors of International Students in the United States. International Journal of Stress Management. 10(2). Pp. 137-157.

8. Murdock, C. Naber, J. Perlow, M.(2010). Stress level and stress management skills of admitted baccalaureate nursing students. Kentucky nurse. 58(2). Pp.8.

9. Toews, J. Lockyer, J. Dobson, D. Simpson, E. Brownell, A. Brenneis, F. MacPherson, K. Cohen, G. (1997). Analysis of stress levels among medical students, resident, and graduate students at four Canadian schools of medicine. Academic Medicine. 72(11). Pp. 997-1002.

10. Bayram, N. Bilgel, N.(2008). The prevalence and socio-demographic correlations of depression, anxiety and stress among a group of university students. Social psychiatric epidemiology. 43(1). Pp 667-672.

11. Amponsah, M. Owolabi, H. (2011). Perceived Stress Levels of Fresh University Students in Ghana. British Journal of Educational Research. 1(2). Pp 153-169. 